\title{
Lactic acid production by a strain of Lactococcus lactis subs lactis isolated from sugar cane plants
}

\author{
Liliana Serna Cock* \\ Departamento de Ingeniería de Alimentos \\ Facultad de Ingeniería \\ Universidad del Valle, Cali, Colombia \\ Tel: 5723307285 \\ E-mail: lilicock@univalle.edu.co \\ Aida Rodríguez de Stouvenel \\ Departamento de Ingeniería de Alimentos \\ Facultad de Ingeniería \\ Universidad del Valle, Cali, Colombia \\ Tel: 5723307285 \\ E-mail: aidrodri@univalle.edu.co
}

Financial support: Universidad del Valle, Cali, Colombia.

Keywords: CC 85-92, leaves of sugar cane, pH control, substrate concentration.

Abbreviations: GC: glucose conversion

$$
\begin{aligned}
& \text { LA: lactic acid } \\
& \mathrm{Y}_{\mathrm{p} / \mathrm{s}}: \text { yield }
\end{aligned}
$$

\begin{abstract}
A Lactococcus lactis subs lactis strain was selected from 20 lactic acid strains isolated from the leaves of sugar cane plants, variety CC 85-92. The effects of substrate concentration and $\mathrm{pH}$ control on lactic acid (LA) production, glucose conversion (GC) and yield $\left(\mathrm{Y}_{\mathrm{p} / \mathrm{s}}\right)$ were investigated using this strain. In batch fermentation at $32^{\circ} \mathrm{C}$, with $60 \mathrm{gl}^{-1}$ of glucose and a $\mathrm{pH}$ of 6.0, concentrations of up to $35 \mathrm{gl}^{-1}$ of lactic acid were obtained. Maximum production and glucose conversion was achieved at low glucose concentrations. The strain shows great potential for lactic acid production from glucose, even without using $\mathrm{pH}$ control during fermentation $\left(13.7 \mathrm{gl}^{-1}\right)$.
\end{abstract}

Lactococcus lactis, originated from the lactic Industrial products have been and are still being, extensively studied for their commercial potential, but that strain isolated from plants has been given less attention (Martínez-Cuesta et al. 1997; Van Niel and Hahn-Hagerdal, 1999); in sugar mills, Lactococcus lactis, like many other lactic acid bacteria, are involved in sucrose inversion, due to their potential for producing lactic acid. However, the commercial potential of these strains that are well adapted to sucrose-rich environments has not been researched, and there are no studies in the scientific literature in which lactic acid production is quantified for each of the strains involved in sucrose inversion.

Lactococcus are coccibacteria, which form chains of variable length, they have a homo-fermentative metabolism and produce exclusively L(+) lactic acid (Roissart, 1994), although Akerberg et al. (1998) report that, D(-) lactic acid can be produced at low $\mathrm{pH}$. Furthermore Lactococcus lactis is sub-divided into other sub-species: lactis and cremoris (Schleifer and Kilpper-Balz, 1987; Kim et al. 1999).

Representatives of this genus are isolated mainly from fresh vegetables and from the skin of animals; therefore it is believed that their presence in milk is due to contamination during milking, given that fodder represents the principal contamination source. Its presence in human being or animals is accidental because of they are not normally found in a significant number in excrement or soil (Roissart, 1994). Their most important habitat is in untreated milk, fermented milk and cheeses. Lactococcus lactis subs lactis, either in pure form or associated with other microorganisms, is the mesophilic strain most commonly used as a starter culture for lactic products; thus they fulfill an irreplaceable role in ensuring the structure, taste, conservation and healthfulness of these products (Jensen y Hammer, 1993; Salminen, and Von Wright, 1993; Roissart, 1994; Boonmee et al. 2003; Ziadi et al. 2005; Do-Won et al. 2006); they also play an important role in aroma enhancement, the production of flavoured milks, and in milk and cheese flavourings, and recently a great deal of attention has been focused on their pro-biotic properties (Salminen, and Von Wright, 1993; Van Niel and Hahn-Hagerdal, 1999; Boonmee et al. 2003). For these reasons this microorganism has great commercial potential,

* Corresponding author 
and this is why Lactococcus, and more especially Lactococcus lactis, isolated in the lactic industry, is still being studied exhaustively. The major product of fermentation is lactic acid, a compound with a high commercial value, with applications in the food, cosmetic, medical, and pharmaceutical industries. (Boonmee et al. 2003). However, the most interesting application for the lactic acid is its potential in the production of biopolymers (Hujanen and Linko, 1996; Chang et al. 1999; Hujanen et al. 2001; Danner et al. 2002; Lee, 2005).

Production of biomass for starter cultures, and of metabolites of Lactococcus lactis, is carried out in batch, fedbatch, and continuous fermentations (Roukas and Kotzekidou, 1998; Ohashi et al. 1999; Akerberg and Zacchi, 2000; Boonmee et al. 2003), and membrane technologies have been used for recovery of the lactic acid (Ohashi et al. 1999; Akerberg and Zacchi, 2000; Danner et al. 2002). In these processes the microorganism can be used either in a free form, or immobilized (Roukas and Kotzekidou, 1991).

It is well-known that the quantity of nutrients required by this strain, as well as its optimal physical growth conditions, depends on the source it was isolated from, how long it has been stored and the medium used to maintain it (Van Niel and Hahn-Hagerdal, 1999). The growth of Lactococcus lactis is greatly influenced by the temperature, and it has only been studied in a few cases; Akerberg et al. (1998), found that $33.5^{\circ} \mathrm{C}$ is the temperature which Lactococcus lactis produces the biggest quantity of lactic acid from glucose. The influence of $\mathrm{pH}$ on various characteristics has been well-studied; the optimum $\mathrm{pH}$ established for growth and product formation is at around 6.0 (Bibal et al. 1988; Parente et al. 1994; Akerberg et al. 1998). Mathematical models have been developed to explain the influence of the substrate concentration on microorganism growth and lactic acid production in high lactose concentrations, they include terms for the inhibition by product and by substrate (Boonmee et al. 2003); other mathematical models include also terms for the $\mathrm{pH}$ and temperature influence (Akerberg et al. 1998; Parente et al. 1994).

As discussed above, and bearing in mind the lack of research on Lactococcus that are isolated from sucrose-rich ecosystems, this paper presents the results obtained from fermentations using glucose and a strain of Lactococcus lactis subs lactis isolated from sugar cane plants and also the effect of substrate concentration and $\mathrm{pH}$ control on $\mathrm{AL}$, GC and $\mathrm{Y}_{\mathrm{p} / \mathrm{s}}$.

\section{MATERIALS AND METHODS}

\section{Sucrose-rich ecosystems}

Samples were taken from 12.3 month-old sugar cane plants, of the CC85-92 variety, and from sugar cane juice, at La Cabaña farm and sugar refinery (Cauca, Colombia). Samples were collected from the point of union between leaves and stem (LUS), from the surface of the leaves (SL), from exudates produced by the cane-borer insect Diatraea saccharalis (EX), and from the first, second and third thirds of the cane stalk (FCS, SCS, TCS). The samples taken at the sugar refinery came from sugar cane juice untreated with lime (CJ), from sugar cane juice with added lime (CJSL); from unfiltered juice (JunF), from filter residues (FR) and from the first pressing (FP). Samples were transported under refrigeration to the bioconversions laboratory at Universidad del Valle, Cali, Colombia.

\section{Isolation of microorganisms}

Each of the samples was diluted sufficiently to obtain isolated colonies, using $0.1 \%$ peptone water, and each was planted in duplicate in MRS agar (De Man et al. 1960). The medium was sterilized at $121.1^{\circ} \mathrm{C}$ and its $\mathrm{pH}$ was adjusted to 6.2 using sulfuric acid. $2 \mathrm{ml} / \mathrm{l}$ of aniline blue was added when the culture medium was at a temperature of $50^{\circ} \mathrm{C}$. The medium was inoculated with $0.1 \mathrm{ml}$ of each of the dilutions using the spread plate method and they were incubated at $36^{\circ}$ and $45^{\circ} \mathrm{C}$ for 48 hrs in anaerobic conditions. The

Table 1. Kineticparameters obtained from batch fermentation with $\mathrm{pH}$ control and without $\mathrm{pH}$ control at different glucose concentrations.

\begin{tabular}{|c|c|c|c|c|c|c|}
\hline \multirow{2}{*}{ Kinetic parameters } & \multicolumn{2}{|c|}{ 20g/l glucose } & \multicolumn{2}{|c|}{$60 \mathrm{~g} / \mathrm{l}$ glucose } & \multicolumn{2}{|c|}{$110 \mathrm{~g} / \mathrm{l}$ glucose } \\
\hline & + & - & + & - & + & - \\
\hline Fermentation time to achieve Pmax (h) & 10 & 48 & 48 & 48 & 48 & 24 \\
\hline Glucose conversion, $100 *($ So-S)/So (\%) & 92.49 & 73.03 & 90.26 & 23.2 & 57.08 & 16.23 \\
\hline Max. cellular concentration, Xmax (g/l) & 2.2 & 1 & 2.57 & 1.33 & 2.7 & 1.13 \\
\hline Max. lactic acid concentration, Pmax (g/l) & 10.2 & 13.7 & 32.3 & 10.09 & 30.04 & 6.26 \\
\hline Product yield, Yp/s (g/g) & 0.54 & 0.8 & 0.63 & 0.78 & 0.45 & 0.27 \\
\hline Lactic acid productivity (g/lh) & 1.0 & 0.29 & 0.67 & 0.21 & 0.63 & 0.26 \\
\hline
\end{tabular}

+ :with $\mathrm{pH}$ control.

-: without $\mathrm{pH}$ control. 
medium was inoculated with $0.1 \mathrm{ml}$ of each of the dilutions (on the surface) and they were incubated at $36^{\circ}$ and $45^{\circ} \mathrm{C}$ for $48 \mathrm{hrs}$ in anaerobic conditions. After counting the presumed organic acid-producing colonies (which assimilated the aniline blue), pure culture was obtained from each of the grown morphologies in the medium using successive subcultures. Once the pure cultures were obtained, they were transferred to MRS liquid culture medium, and incubated under the same conditions described above. After 24 hrs the pure liquid cultures were centrifuged at $5000 \mathrm{~g}$ for $10 \mathrm{~min}$ and then filtered with Millipore HVLP02500 filters; the supernatants were then injected into an HPLC.

The strains that produced more than $12 \mathrm{gl}^{-1}$ of lactic acid under the described conditions were stored in MRS culture medium with glycerol, and they were frozen for preservation and later use.

\section{Selection of the strain}

The homo-fermentative strain which produced the highest lactic acid concentration was selected for this study.

\section{Fermentation}

Previous studies showed that the optimal temperature for lactic acid production of the selected strain was $32^{\circ} \mathrm{C}$ (results not shown); thus, for this investigation, 18 fermentation trials were carried out at this temperature, using MRS broth, in $500 \mathrm{ml}$ conical flasks, with a working volume of $250 \mathrm{ml}$. The strain was adapted to the cultivation temperature for three generations.

In order to study the effect of $\mathrm{pH}$ control, fermentations were carried out without $\mathrm{pH}$ control, and with $\mathrm{pH}$ controlled at 6.0, through the manual addition of $4 \mathrm{M}$ sodium hydroxide.

The effect of substrate concentration was studied by varying the glucose concentration in MRS broth, between 20, 60 and 110 grams per litter.

In all cases: $10 \%$ inoculate with respect to volume of substrate was used, a fermentation time of 48 hrs at 120 rpm.

\section{Analytical method}

The strain was biochemical identified by duplicate, using API 50 CHL. The isomeric identification of the produced acid was made by enzymatic analysis D-lactic acid / Llactic acid.

The identification of the glucose metabolism by homofermentative or heterofermentative pathway was made using HPLC, quantifying the concentration of alcohol and acetate in MRS broth after the fermentative process.
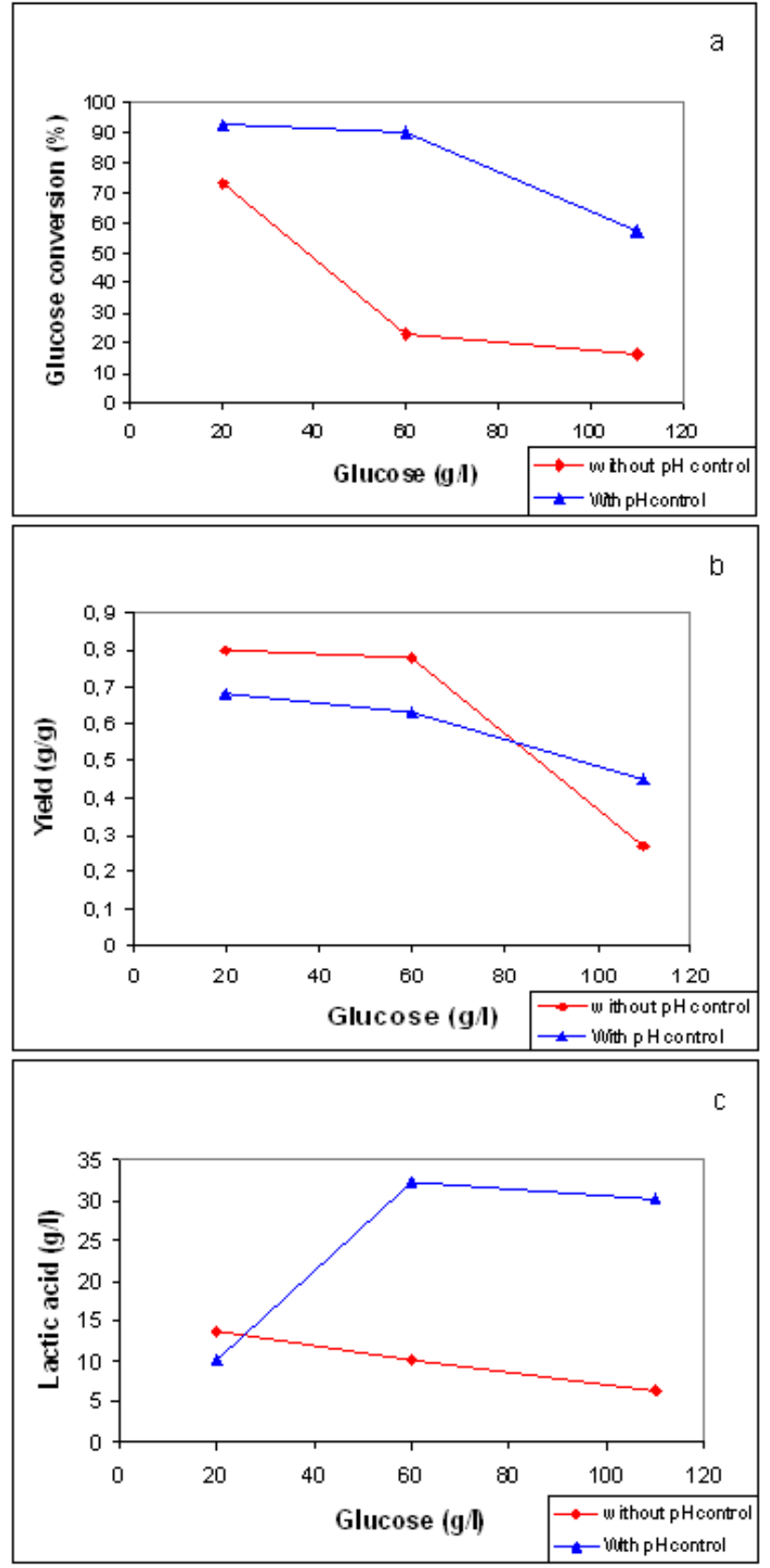

Figure 1. Interaction graphics between glucose concentration and $\mathrm{pH}$ control.

a. Glucose conversion, b. Yield, c. Lactic acid concentration

Samples of the liquid products from fermentation were treated as described above before HPLC analysis. Sugars and lactic acid concentrations were measured using highefficiency liquid chromatography, HPLC (Hitachi L6000A, integrator D-2500, equipped with an Aminex HPX $87 \mathrm{H}, 300 \mathrm{~mm}$ column), working temperature for the column was $60^{\circ} \mathrm{C}$, mobile phase was sulfuric acid $0.005 \mathrm{M}$ and flow rate was of $0.6 \mathrm{ml} / \mathrm{second}$. Biomass was calculated as $540 \mathrm{~nm}$ from optical density data, using a spectrum-photometer (Milton Roy 401). The $\mathrm{pH}$ was measured with an $\mathrm{pH}$ meter (ORION 710A). 
The percentages of substrate conversion (GC) were calculated using the following expression:

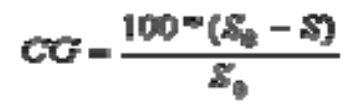

$S_{0}$ : initial glucose concentration $\left(\mathrm{gl}^{-1}\right)$

$S$ : Final glucose concentration $\left(\mathrm{gl}^{-1}\right)$, to time when $\mathrm{P}$ is maximum

The yields $\left(\mathrm{Y}_{\mathrm{p} / \mathrm{s}}\right)$ in grams per gram, were calculated as the gradient of the curve obtained by plotting product concentration against substrate concentration.

\section{Reactives}

Reactive grade products were used (Sigma Chemical Co.).

\section{Statistical design}

A factor design of $2 \times 3$, with three replicates, was used to analyze the effect of glucose concentration and $\mathrm{pH}$ control on AL, GC and $\mathrm{Y}_{\mathrm{p} / \mathrm{s}}$. The $\mathrm{pH}$ was evaluated with two levels, using $\mathrm{pH}$ control and the other without $\mathrm{pH}$ control, and glucose concentration was evaluated at three levels: 20, 60 and $110 \mathrm{gl}^{-1}$. The data obtained was analyzed by Analysis of Variance (ANOVA) using MINITAB version 14 statistical software.

\section{RESULTS}

\section{Selection of the strain}

20 strains isolated from LUS, SL, EX, FCS, SCS, CJ and CJSL were selected for production of lactic acid, of which only one homo-fermentative strain produced significant quantities $\left(12.4 \mathrm{~g} \mathrm{l}^{-1}\right.$ of lactic acid at $36^{\circ} \mathrm{C}$ and $13.7 \mathrm{~g} \mathrm{l}^{-1} \mathrm{a}$ $32^{\circ} \mathrm{C}$ ). None of the strains produced significant quantities of lactic acid at $45^{\circ} \mathrm{C}$. The strain was biochemical identified as Lactococcus lactis subs lactis. The strain produced lactic acid with the isomeric configuration $\mathrm{L}(+)$.

\section{Effect of $\mathrm{pH}$ control and substrate concentration}

The variance analysis showed that glucose concentration and $\mathrm{pH}$ control have a highly significant effect on lactic acid concentration, glucose conversion and product yield ( $\mathrm{P}$ $<0.005$ ) with $\mathrm{S}$ values of $0.4457,0.7696$ and 0.02321 respectively. The interaction graphics (Figure 1) show the combined effects of glucose concentration and $\mathrm{pH}$ control when they change simultaneously. The graphic shows a considerable interaction between $\mathrm{pH}$ and glucose concentration upon lactic acid concentration and yield, as it was already seen in the ANOVA, and less marked interaction effect occurs for the glucose conversion.

The kinetic parameters, calculated from the experimental data, can be seen in Table 1, while the kinetics of lactic acid production and of substrate consumption can be seen in Figure 2 and Figures 3 respectively.

The highest glucose concentration was achieved with $60 \mathrm{~g}$ $\mathrm{l}^{-1}$ of glucose and with $\mathrm{pH}$ control (Figure 2); Ackerberg et al. (1998) found that the maximum glucose concentration for lactic acid production by Lactococcus lactis ssp lactis is $80 \mathrm{gl}^{-1}$. It is also important to highlight the good performance of the strain at low glucose concentrations (20 $\mathrm{gl}^{-1}$ ) without $\mathrm{pH}$ control, in terms of lactic acid production and yield; in this case product generation was associated with growth, with an $r_{p}$ of $0.29 \mathrm{gl}^{-1} \mathrm{~h}^{-1}$. In other cases, lactic acid was associated, and non-associated, with growth; Boonmee et al. (2003) using lactose and Lactococcus lactis, report this same behaviour. Working with concentrations of 20 to $40 \mathrm{gl}^{-1}$, they found that the production of $\mathrm{AL}$ is associated, and non-associated, with growth.

The highest $\mathrm{Y}_{\mathrm{p} / \mathrm{s}}$ were obtained at low glucose concentrations and without $\mathrm{pH}$ control, while the largest percentages of $G C$ were obtained with low glucose concentrations, but with $\mathrm{pH}$ control.

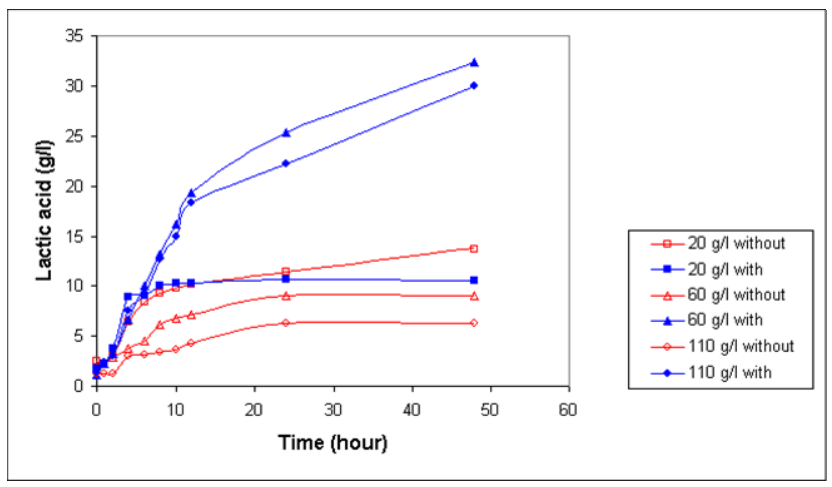

Figure 2. Kinetics of lactic acid production at different glucose concentration, with $\mathrm{pH}$ control and without $\mathrm{pH}$ control.

\section{DISCUSSION}

As can be seen in Figure 2, the fermentations with controlled $\mathrm{pH}$ using 60 and $110 \mathrm{~g} \mathrm{l}^{-1}$ of glucose showed the same kinetic behaviour for lactic acid production. However, glucose conversion when $110 \mathrm{gl}^{-1}$ was used is only $57 \%$. This value is far lower than the obtained value when using $60 \mathrm{gl}^{-1}$, when glucose conversion is $90.2 \%$ (Table 1); this last situation is considered ideal in batch type fermentations, due to the product purification costs are lower. The significant concentration of lactic acid obtained in $48 \mathrm{hrs}$ of fermentation with $20 \mathrm{gl}^{-1}$ of glucose, and without $\mathrm{pH}$ control $\left(13.7 \mathrm{gl}^{-1}\right)$ can be explained by the adaptation of the strain to environments with high sucrose concentrations and besides because it has been demonstrated that Lactococcus lactis ssp. lactis is capable of surviving and replicating in more extreme levels of stress, compared to other lactic acid strains (Kim et al. 1999). This is why the microorganism has an enzymatic 
system that hydrolyzes the disaccharide and then metabolizes the glucose using the glycolytic pathway; the behaviour of this isolation in substrates rich in sucrose was studied by Serna-Cock and Rodriguez-de Stouvenel (2004). The lower lactic acid concentration obtained using $20 \mathrm{gl}^{-1}$ and $\mathrm{pH}$ control is due to an evident limitation of substrate.

In both the trials using $\mathrm{pH}$ control and those without $\mathrm{pH}$ control, it was observed that, as the glucose concentration is increased, the GC and $\mathrm{Y}_{\mathrm{p} / \mathrm{s}}$ decrease, phenomenon that can occur by substrate inhibition, product inhibition or exhaustion of one restricting nutrient or their combined effect, however, concentrations of lactic acid obtained using 60 and $110 \mathrm{gl}^{-1}$ of glucose do not differ significantly. This behaviour is also reported by Kious, 2000, in batch type lactic fermentations without $\mathrm{pH}$ control and with varying glucose concentrations from $20 \mathrm{gl}^{-1}$ to $100 \mathrm{gl}^{-1}$; the results for lactic acid concentrations, yields and glucose conversion obtained by this author are similar to those reported in this study. Hujanen, 2001, also reports inhibition by substrate in fermentations with $\mathrm{pH}$ controlled at 6.3, using Lactobacillus casei NRRL B-441, and varying the glucose concentration between 80 and $160 \mathrm{gl}^{-1}$.

The strain of Lactococcus lactis subs lactis isolated from the leaves of variety CC-8592 sugar cane shows great potential for lactic acid production using glucose as substrate, even without using $\mathrm{pH}$ control during fermentation. Since there has been little studies

Lactococcus isolated from plant material, the results presented here suggest the importance of evaluating the genetic and commercial potential of this microorganism isolated from sugar cane, and also of other lactic acid bacteria adapted to substrates different to the lactose.

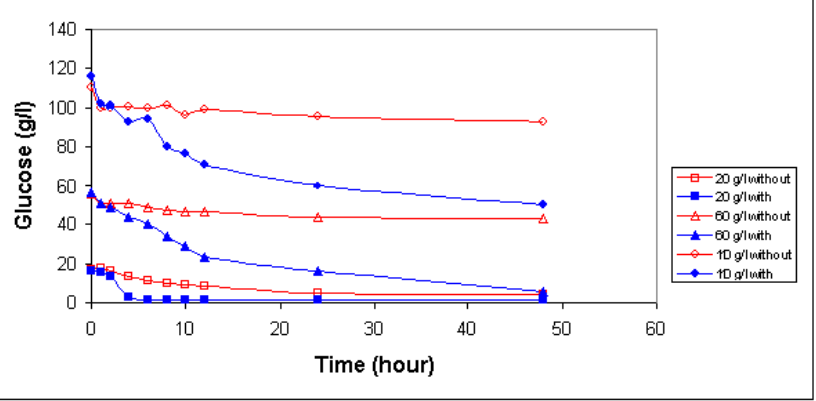

Figure 3. Kinetics of substrate consumption at different glucose concentration, with $\mathrm{pH}$ control and without $\mathrm{pH}$ control

\section{ACKNOWLEDGEMENTS}

The authors would like to thank the Centro de Investigación de la caña de azúcar (Centre for sugar cane studies), CENICAÑA and Ingenio La Cabaña (La Cabaña sugar cane processing plant) for their help in carrying out this study.

\section{REFERENCES}

AKERBERG, Christina and ZACCHI, Guido. An economic evaluation of the fermentative production of lactic acid from wheat flour. Bioresource Technology, 2000,vol.75, no. 2, p. 119-126.

AKERBERG, C.; HOFVENDAHL, K.; ZACCHI, G. and Hahn-Hagerdal, B. Modeling the influence of $\mathrm{pH}$, temperature, glucose and lactic acid concentration on the kinetics of lactic acid production by Lactococcus lactis ssp. lactis ATCC 19435 in whole-wheat flour. Applied Microbiology and Biotechnology, 1998, vol. 49, no. 6, p. 682-690.

BIBAL, B.; GOMA, G.; VAYSSIER, Y. and PAREILLEUX, A. Influence of $\mathrm{pH}$, lactose and lactic acid on the growth of Streptococcus cremoris: a kinetic study. Applied Microbiology and Biotechnology, 1988, vol. 28, no. 4-5, p. 340-344.

BOONMEE, Mallika; LEKSAWASDI, Noppol; BRIDGE, Wallace and ROGERS, Peter. Batch and Continuous culture of Lactococcus lactis NZ133: experimental data and model development. Biochemical Engineering Journal, 2003, vol.14, no. 2, p. 127-135.

CHANG, Dong-Eun; JUNG, Heung-Chae; RHEE, JoonShick and PAN, Jae-Gu. Homofermentative production of D- or L-Lactate in metabolically engineered Escherichia coli RR1. Applied and Environmental Microbiology, 1999, vol. 65 , no. 4, p. 1384-1389.

DANNER, H.; MADZINGAIDZO, L.; THOMASSER, C.; NEUREITER, $M$. and BRAUN, R. Thermophilic production of lactic acid using integrated membrane bioreactor systems coupled with monopolar electrodialysis. Applied Microbiology and Biotechnology, 2002, vol. 59, no 2-3, p. 160-169.

DE MAN, J.C.; ROGOSA, M. and SHARPE, M.E. A medium for the cultivation of Lactobacilli. Journal Applied Bacteriology, 1960, vol. 23, p. 130-135.

DO-WON, Jeonga; YOUN CHUL, Choia; JUNG MIN, Leea; JEONG HWAN, Kimb; JONG-HOON, Leec; KYOUNG HEON, Kimd and HYONG JOO Leea. Isolation and characterization of promoters from Lactococcus lactis ssp. cremoris LM0230. Food Microbiology, February 2006, vol. 23, no. 1, p. 82-89.

HUJANEN, M.; LINKO, S.; LINKO, Y. and LEISOLA, M. Optimization of media and cultivation conditions for $\mathrm{L}(+)$ (S)-lactic acid production by Lactobacillus casei NRRL B441. Applied Microbiology and Biotechnology, 2001. vol. 56, no. 1-2, p. 126-130.

HUJANEN, M. and LINKO, Y-Y. Effect of temperature and various nitrogen sources on $\mathrm{L}(+)$ lactic acid production 
by Lactobacillus casei. Applied Microbiology and Biotechnology, 1996, vol. 45, no. 3, p. 307-313.

JENSEN, P.R. and HAMMER, K. Minimal requirements for exponential growth of Lactococcus lactis. Applied Environmental Microbiology, 1993, vol. 59, no. 12, p. 4363-4366.

KIM, Woojin S.; REN, Jun and DUNN, Noel W. Differentiation of Lactococcus lactis subspecies lactis and subspecies cremoris strains by their adaptive response to stresses. FEMS Microbiology Letters, February 1999, vol. 171, no. 1, p. 57-65.

KIOUS, Jessica J. Lactobacillus and lactic acid production [online]. Energy Research Undergraduate Laboratory Fellowship Program (ERULF), National Renewable Energy Laboratory, Colorado, 2000 [cited February 2002]. Portable Document Format. Available from Internet: http://www.nrel.gov/docs/gen/fy01/NN0017.pdf.

LEE, Kibeom. A media design program for lactic acid production coupled with extraction by electrodialysis. Bioresource Technology, 2005, vol. 96, no. 13, p. 15051510.

MARTÍNEZ-CUESTA, M. Carmen; PELÁEZ, Carmen; JUÁREZ, Manuela and REQUENA, Teresa. Autolysis of Lactococcus lactis ssp. lactis and Lactobacillus casei ssp. casei. Cell lysis induced by a crude bacteriocin. International Journal of Food Microbiology, September 1997,vol. 38,no. 2-3,p. 125-131.

OHASHI, Ryo; YAMAMOTO, Tomonori and SUZUKI, Takahiro. Continuous production of lactic acid from molasses by perfusion culture of Lactococcus lactis using a stirred ceramic membrane reactor. Journal of Bioscience and Bioengineering, 1999, vol. 87, no. 5, p. 647-654.

PARENTE, E.; RICCIARDI, A. and ADDARIO, G. Influence of $\mathrm{pH}$ on growth and bacteriocin production by Lactococcus lactis ssp lactis 140NWC during batch fermentation. Applied Microbiology and Biotechnology, 1994, vol. 41, no. 4, p. 388-394.

ROISSART, H. and Luquet F.M. Bactéries lactiques: aspects fondamentaux et technologiques. Uriage, Lorica, France, 1994, vol. 1, p. 605. ISBN 2950747701.

ROUKAS, T. and KOTZEKIDOU, P. Production of lactic acid from deproteinized whey by coinmobilized Lactobacillus casei and Lactococcus lactis cell. Enzyme and Microbial Technology, 1991, vol. 13, no. 1, p. 33-38.

ROUKAS, T. and KOTZEKIDOU, P. Lactic acid production from deproteinized whey by mixed cultures of free and coinmobilized Lactobacillus casei and Lactococcus lactis cells using fedbatch culture. Enzyme and Microbial Technology, 1998, vol. 22, no. 3, p. 199-204.
SALMINEN, S. and VON WRIGHT, A. Lactic Acid Bacteria. Marcel Dekker Ltd., New York, 1993. 442 p. ISBN: 0824789075.

SCHLEIFER, K.H. and KILPPER-BALZ, R. Molecular and Chemotaxonomic approaches to the classification of Streptococci, Enterococci and Lactococci: a review system. Applied Microbiology, 1987, vol. 10, no. 1, p. 1-9.

SERNA-COCK, Liliana and RODRIGUEZ-DE STOUVENEL, Aida. Jugo de caña verde como sustrato en la producción fermentativa en discontinuo de ácido láctico. Revista Colombiana de Biotecnología, 2004, vol 6, no. 2, p. 37-42.

VAN NIEL, E.W.J. and HAHN-HAGERDAL, B. Nutrient requirements of Lactococci in defined growth media. Applied Microbiology and Biotechnology, 1999, vol. 52, no. 5, p. 617-627.

ZIADI, M.; TOUHAMI, Y.; ACCHOUR, M.; THONART, $\mathrm{Ph}$. and HAMDI, M. The effect of heat stress on freezedrying and conservation of Lactococcus. Biochemical Engineering Journal, 2005, vol. 24, no. 2, p. 141-145. 